\title{
High-resolution transmission electron microscopy investigation of in situ $\mathrm{TiC} / \mathrm{Al}$ composites
}

\author{
O. Duygulu
}

TUBITAK Marmara Research Center, Kocaeli 41470, Turkey

Received 5 July 2017, received in revised form 12 July 2018, accepted 18 July 2018

\begin{abstract}
$\mathrm{TiC} / \mathrm{Al}$ metal matrix composites (MMCs) were produced by in situ reactive hot pressing (RHP) technique. Aluminum, titanium, and graphite powders were used as starting materials. The powders were cold-pressed, rapidly heated to $1200^{\circ} \mathrm{C}$, sintered, and then hot pressed. The microstructure and $\mathrm{TiC}$ particles were investigated via $\mathrm{X}$-ray diffraction, micro-hardness testing, high resolution scanning electron microscopy-energy dispersive spectrometry, highresolution transmission electron microscopy-energy dispersive spectrometry, and selected area electron diffraction/electron backscattered diffraction-transmission electron microscopy. The properties of the $\mathrm{Al}$ matrix and $\mathrm{TiC}$ interface were also studied. At $1200^{\circ} \mathrm{C}$, only the $\mathrm{TiC}$ secondary phase was observed in X-ray diffraction. A hardness value of $99 \mathrm{HV}$ was measured. Scanning electron microscopy and transmission electron microscopy studies revealed submicron and mostly nanosized TiC particles. Round, rod type, and irregularly shaped particles were observed. Transmission electron microscopy examinations showed a clean interface between the in situ $\mathrm{TiC}$ reinforcements and aluminum matrix.
\end{abstract}

K e y w o r d s: metal matrix composite, TiC, aluminum, scanning electron microscopy, transmission electron microscopy, microstructure

\section{Introduction}

Metal matrix composites (MMC) have high specific strength with good specific modulus, hardness, wear resistance, and thermal stability [1-15]. They are used in such diverse areas as aerospace, automotive, defense, and structural applications [8, 9]. They are affordable tools in various applications.

The reinforcement type of MMCs can be continuous or discontinuous. Discontinuous reinforcements include particles, short fibers, or whiskers. They offer affordable and facile production [9]. They can also improve the properties of the matrix material while preserving the isotropic properties of composites. Conventional MMCs with discontinuous reinforcements are produced by ex situ techniques including powder metallurgy, squeeze casting, rheocasting, compocasting, mechanical alloying, and spray deposition [1-9].

New types of MMCs are mostly produced by in situ techniques with better interface bonding, mechanical properties, and thermal properties. This method provides very fine carbides, nitrides, borides, oxides, or their mixtures. It can be applied to titanium, aluminum, copper, iron, or nickel at scale [9].

In situ processing routes can be classified into four categories: (a) solid-liquid reactions; (b) vapor-liquidsolid reactions; (c) solid-solid reactions, and (d) liquidliquid reactions [9]. Solid-liquid reaction processes have different sub-types such as self-propagating hightemperature synthesis (SHS), exothermic dispersion (XD), reactive hot pressing (RHP), rapid solidification processing (RSP), combustion assisted casting (CAC), direct reaction synthesis (DRS), flux-assisted synthesis (FAS) (also known as mixed-salt reaction or reaction cast), reactive spontaneous infiltration (RSI), directed melt/metal oxidation (DIMOX), and reactive squeeze casting (RSC) [9]. Similarly, the solid-solid reaction processes are mechanical alloying (MA), reactive hot pressing (RHP), and isothermal heat treatment (IHT) [9].

The reactive hot pressing (RHP) process is mainly a solid-liquid reaction process developed by $\mathrm{Ma}$ et

*Corresponding author: tel.: +902626773132; e-mail address: ozgur.duygulu@tubitak.gov.tr 


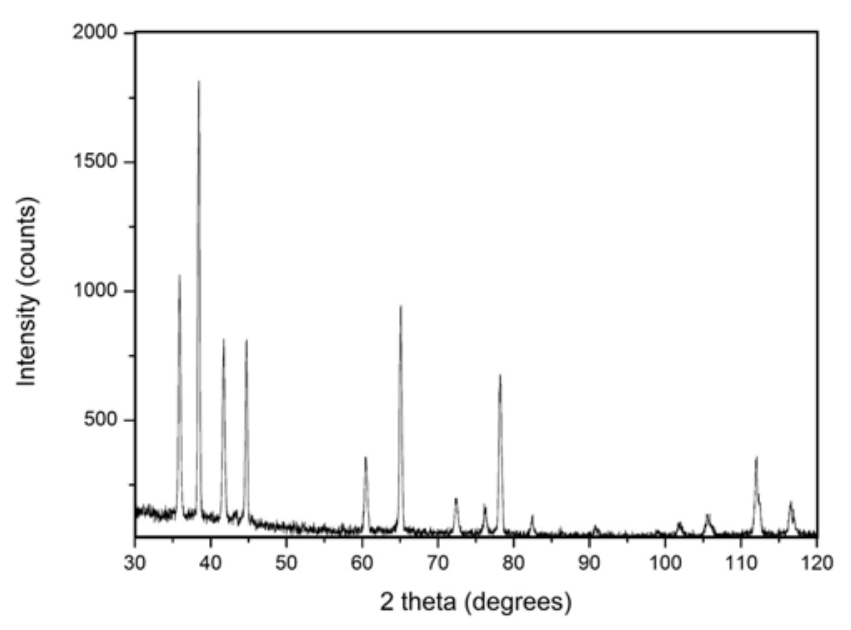

Fig. 1. X-ray diffraction spectrum.

al. $[9,16]$. It is an exothermic dispersion (XD) technique [17]. Ma and coauthors used $\mathrm{TiB}_{2}$ particles and whiskers in the aluminum and titanium matrix $[16$, $18,19]$. In RHP, exothermic conversion of the reactants to the reinforcements and the hot compaction of the porous composite product are enclosed, and dense MMCs can be produced in a single step [9].

Aluminum-based metal matrix composites are one of the most common MMCs. They are generally used for advanced structural, automobile, chemical, and aerospace applications where high specific strength, specific modulus, and good high-temperature resistance are needed $[2,7,13,15,20-23]$. Particle- -reinforced MMCs are the most common. They have easy production and isotropic properties [20].

$\mathrm{TiC}$ is a good particle reinforcement tool for aluminum MMCs. It has a high melting point, hardness, stiffness, wear resistance, thermal, and electrical conductivity as well as a low density [24, 25]. Moreover, $\mathrm{TiC}$ is inexpensive and shows good wetting with aluminum [26]. Combining the properties of $\mathrm{TiC}$ with that of aluminum makes Al-TiC MMCs superior [26]. $\mathrm{TiC}$ is also used as a grain refiner in aluminum alloys [27].

Several studies have produced $\mathrm{TiC} / \mathrm{Al}$ MMCs via in situ techniques [20]. The microstructure of in situ as-cast $\mathrm{TiC} / \mathrm{Al}$ MMCs mostly show clusters of micronsized TiC particles [20, 28]. Chu et al. studied Al-6 wt.\% Ti alloy-high-purity graphite powders by DTA [29]. They stated that an exothermic reaction occurred at $1533 \mathrm{~K}$ due to the formation of TiC. Zhang et al. stated that the reaction of $\mathrm{TiC}$ with aluminum is a solution-precipitation mechanism. They identified the processing steps as heating and melting, initial reaction, complete reaction, and cooling [30]. Kim et al. studied aluminum matrix composites reinforced by 45-nm-diameter $\mathrm{TiC}$ nanoparticles (1.5-3 vol.\%). They also added carbon nanotubes to $\mathrm{TiC}$ nanoparticles via ball-milling and sheath-rolling [28].

The reinforcement-metal matrix interface is very critical because it affects the mechanical and physical properties of MMCs [9, 31, 32]. One of the most important criteria of processing is wetting of ceramics via liquid metals. The chemical reaction or wetting between the metal matrix and the ceramic reinforce-
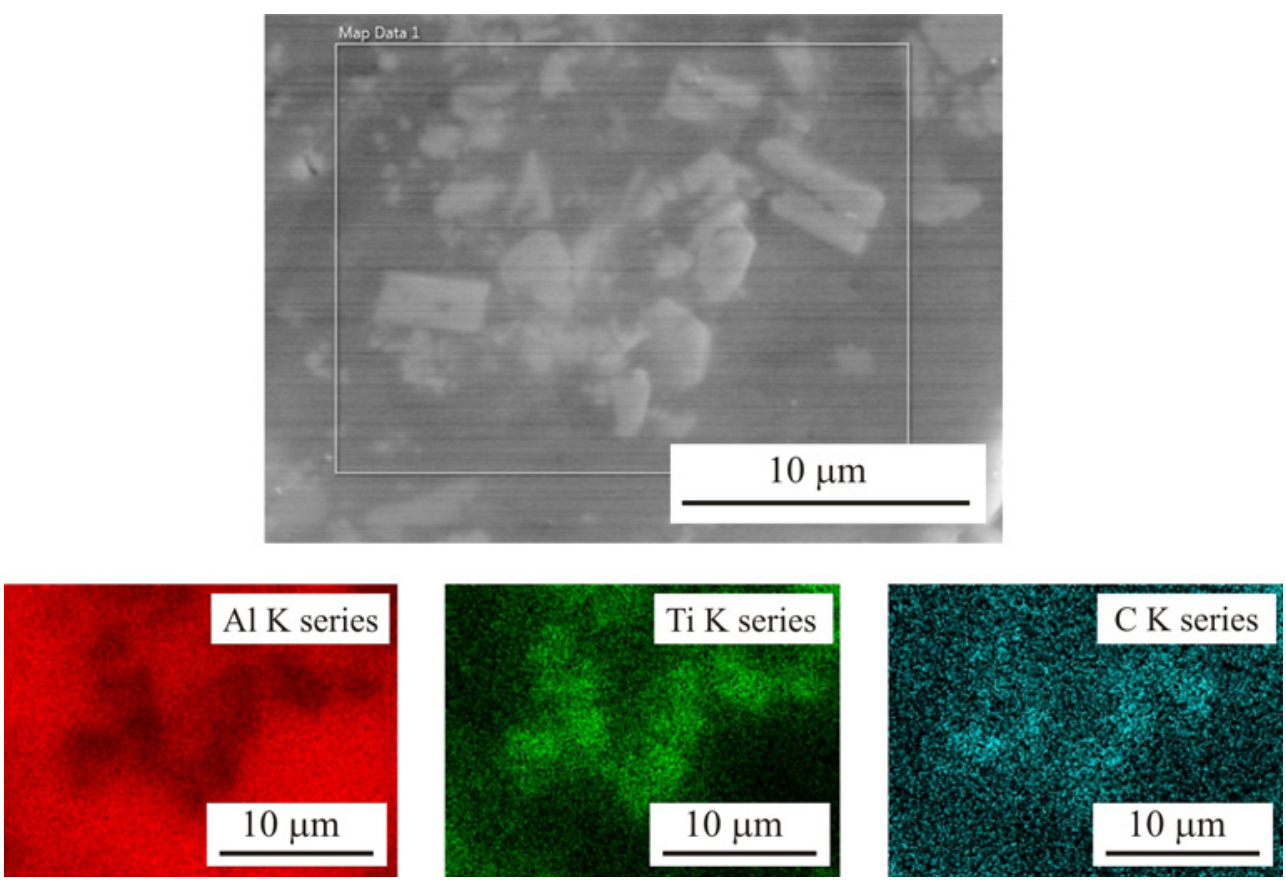

Fig. 2. SEM image of TiC particles and elemental EDS maps from the selected areas. 


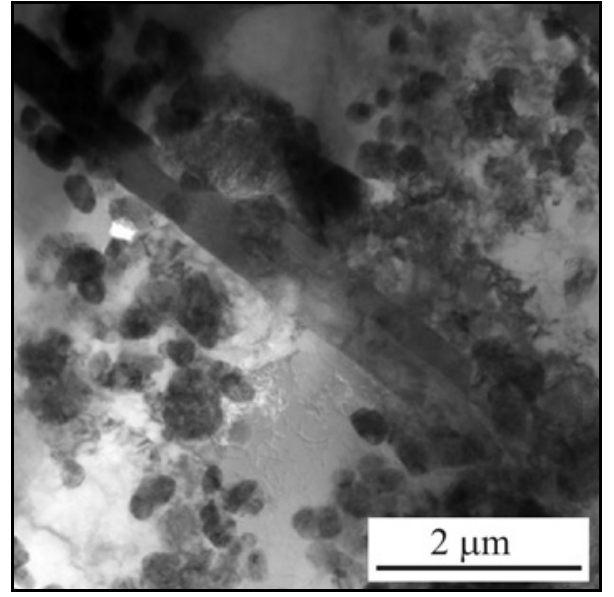

Fig. 3. Low magnification TEM picture showing the particles.

ment affects how the load is transferred at the interface [33-35]. The strength, ductility, stiffness, hardness, fatigue, creep, fracture toughness, the coefficient of thermal expansion, and thermal conductivity prop- erties of the composites depend on the reinforcement and the interface $[9,31,32]$. The in-situ techniques give better properties than ex-situ techniques for most MMCs due to enhanced wettability [9].

Compared to conventional metal matrix composites, the addition of nano-sized reinforcements increases the strength due to Orowan strengthening [28, $36]$. In the literature, these composites are often called nanocomposites or MMNCs (metal matrix nanocomposites). Moreover, nano-sized reinforcements also pin the grain boundaries and reduce the grain size so that the strength increases more [37]. It is known that in situ MMCs have finer and more uniformly distributed reinforcements than ex situ MMCs [9]. Tong et al. used an RSP technique on Al-TiC MMC with 40-80 nm particles that were distributed uniformly in the matrix $[20,38,39]$.

Transmission electron microscopy (TEM) is the best characterization method to study nano-sized particles. Surprisingly, there are not many high-resolution transmission electron microscopy (HRTEM) studies of reinforcements in MMCs, especially for Al-TiC MMC. TEM studies of the production of Al-TiC MMC with
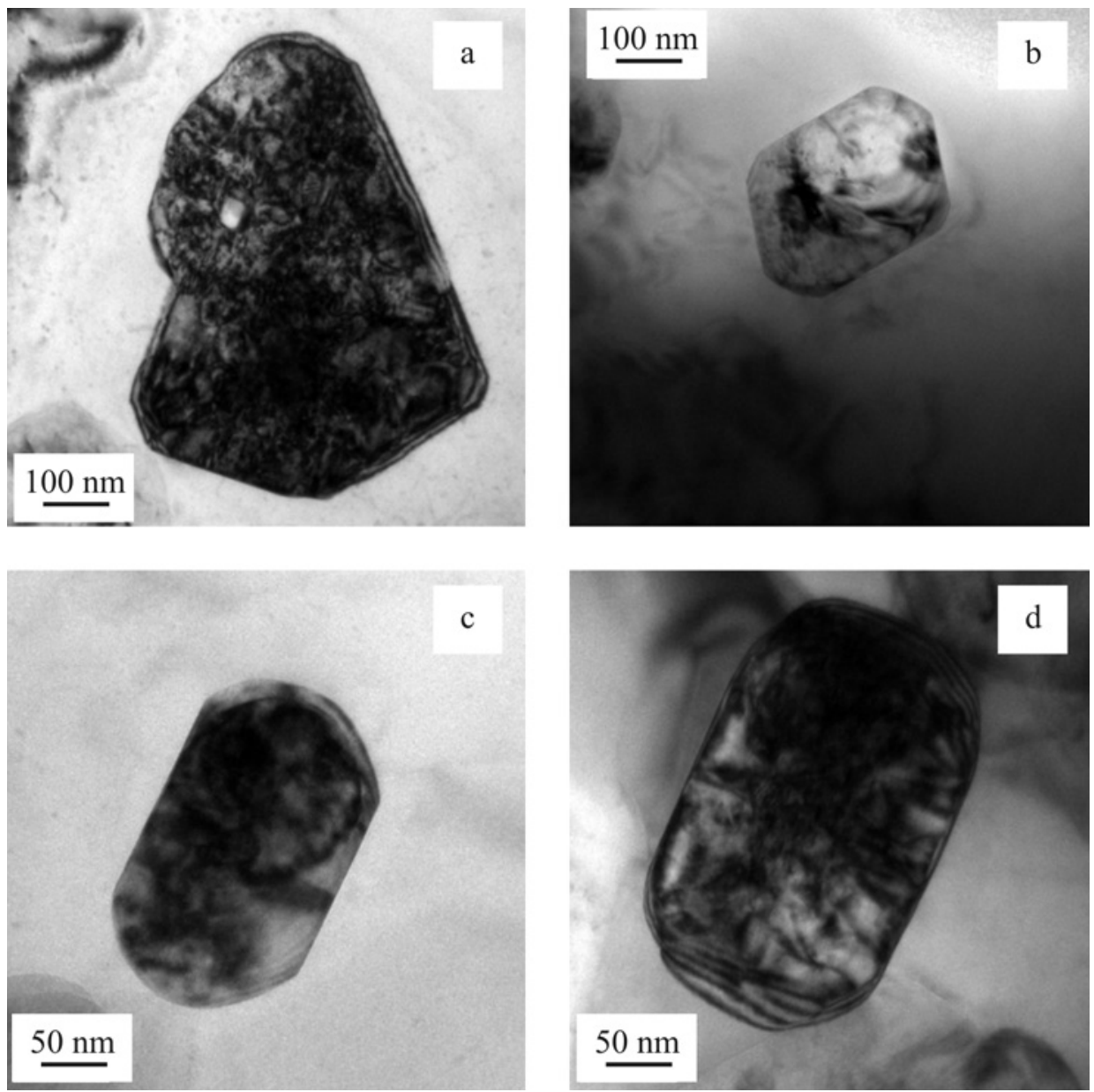

Fig. 4. Irregularly shaped TiC particles. 
current reactive hot pressing (RHP) techniques are rare.

Shi et al. studied a $\mathrm{TiC} / \mathrm{Ti}_{2} \mathrm{AlC} / \mathrm{TiAl}_{3} \mathrm{MMC}$ with a composition of $\mathrm{TiC}-20 \mathrm{Ti}_{2} \mathrm{AlC}-10 \mathrm{TiAl}_{3}$ (vol.\%) via an in situ spark plasma sintering-reactive sintering (SPS-RS) technique [40]. Zhang et al. fabricated $\mathrm{Ti}_{2} \mathrm{AlC} / \mathrm{TiC} / \mathrm{Al}_{2} \mathrm{O}_{3} \mathrm{MMC}$ in situ and studied it with TEM [41]. Cui et al. used TEM on their in situ fabricated TiCp-AlNp/Al composites [42]. The Peng group formed $\mathrm{Al}_{2} \mathrm{O}_{3}-\mathrm{TiC} / \mathrm{Al}$ MMCs with an in situ method [22]. Their TEM studies showed that TiCp-Al interface was clean and free from contaminants [22]. Tong et al. investigated in situ reinforced $\mathrm{TiC}$ Al MMCs with HRTEM-selected area electron diffraction (SAED) and convergent beam electron diffraction (CBED) [10, 20]. Ma et al. used an RHP technique on an $\left(\mathrm{Al}_{2} \mathrm{O}_{3}-\mathrm{TiB}_{2}\right) / \mathrm{Al}$ system and observed the interfaces of $\mathrm{Al}_{2} \mathrm{O}_{3}$ and $\mathrm{TiB}_{2}$ particles by TEM [43]. Mitra et al. used an $\mathrm{XD}$ technique to produce $\mathrm{TiC} / \mathrm{Al}$ and $\mathrm{TiB}_{2} / \mathrm{Al}$ systems. They used TEM, SAED, and HRTEM techniques to study the interfaces [44-46].

3 -D printing and additive manufacturing (AM) studies of metals increased recently in the literature. Selective Laser Melting (SLM) is known to be one of the most effective powder-based additive manufacturing methods for metal parts. $\mathrm{Gu}$ et al. studied the nano-sized $\mathrm{TiC}$ particle reinforced AlSi10Mg nanocomposite parts those were produced by selective laser melting process [47]. Similarly, there are in situ studies of the synthesis of $\mathrm{TiC}$ particles during the mechanical alloying process. Popov et al. studied the in-situ synthesis of $\mathrm{TiC}$ particles in the $\mathrm{Al}$ matrix with mechanical alloying. They used nanodiamonds as a precursor. They obtained the average size of $\mathrm{TiC}$ nanoparticles around $30 \mathrm{~nm}$. They used differential scanning calorimetry and SEM for characterization [48].

In the $\mathrm{Al} / \mathrm{TiC} \mathrm{MMCs}$, the interfacial properties and microstructure of the $\mathrm{Al}$ matrix and the $\mathrm{TiC}$ are not established for the RHP technique. Therefore, this work studied the microstructures of an $\mathrm{Al} / \mathrm{TiC}$ composite that was fabricated by RHP. The goal is to investigate the microstructure of the $\mathrm{TiC}$ reinforcements in the aluminum matrix via TEM and HRTEM.

\section{Experimental procedure}

The $\mathrm{TiC} / \mathrm{Al}$ MMCs were prepared by in situ RHP using $\mathrm{Al}$ (80 vol.\%), Ti (16 vol.\%), and graphite (C) (4 vol.\%) powders. The particle sizes by SEM were as follows: $\mathrm{Al}$ at $1-10 \mu \mathrm{m}, \mathrm{Ti}$ at $10-30 \mu \mathrm{m}$, and $\mathrm{C}$ below $10 \mu \mathrm{m}$. The powders were first uniaxially cold-pressed at 100 bar. The powders were then rapidly heated to $1200^{\circ} \mathrm{C}$ and sintered under argon (Ar) atmosphere for half an hour; finally, the samples were hot pressed at 3 bar at a semi-solid/liquid temperature and cooled.
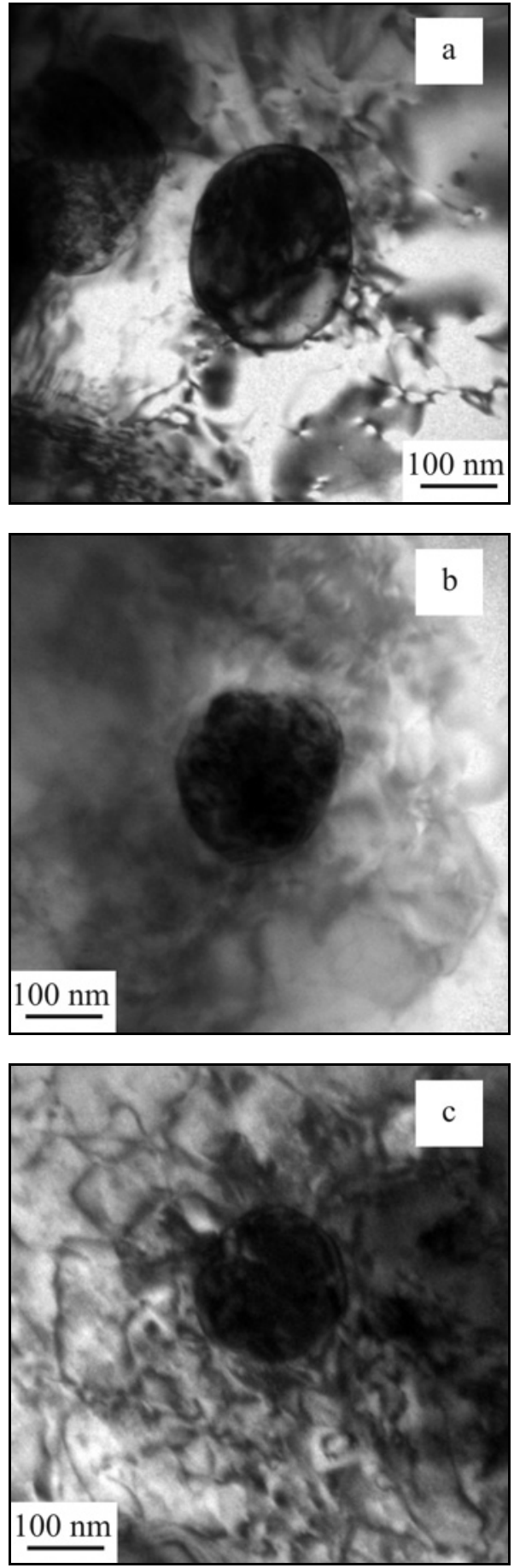

Fig. 5. TEM pictures of round TiC particles.

The details of the experimental setup are given elsewhere [49].

The Vickers microhardness measurements were performed with a $200 \mathrm{~g}$ applied load using a Qness hardness device. For X-ray diffraction (XRD) studies, the specimens were polished, and a PANanalytical $\mathrm{X}$ 'Pert Pro diffractometer producing $\mathrm{Cu}-\mathrm{K} \alpha$ radiation at $45 \mathrm{kV}$ and $40 \mathrm{~mA}$ was used. The high resolution 


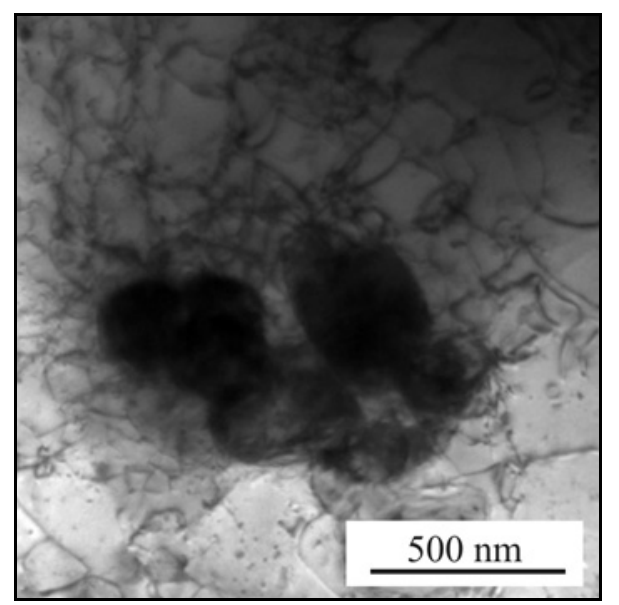

Fig. 6. TEM picture showing the dislocations around the irregularly shaped $\mathrm{TiC}$ particles.

scanning electron microscope (HRSEM) observations were carried out using a JEOL JSM $6335 \mathrm{~F}$ field emission gun (FEG) SEM operated at $20 \mathrm{kV}$ equipped with $80 \mathrm{~mm}^{2}$ X-MaxN Oxford Instruments energy dispersive spectrometry (EDS) system and AZtec software.

For TEM studies, specimens were cut with a Struers Minitom low-speed diamond saw. Thin foils were prepared by disc punching $3 \mathrm{~mm}$ disks and grinding them down to $\sim 150 \mu \mathrm{m}$. After perforation, the samples were electropolished with an electrolyte containing $25 \%$ nitric acid $+75 \%$ methanol solution at about $-30{ }^{\circ} \mathrm{C}$ with $15 \mathrm{~V}$ in Struers-Tenupol-5 Double Jet Electropolisher. A Gatan 691 Precision Ion Polishing System (PIPS) was also used for HRTEM. Before PIPS, 3-mm disks were first ground to $60 \mu \mathrm{m}$. The center was then thinned down to $\sim 10 \mu \mathrm{m}$ with a Gatan 656 Dimple Grinder. Some electropolished specimens were further ion milled - the specimens were first ion polished at $4 \mathrm{kV}$, and then a transparent area was achieved at a final step of $2 \mathrm{kV}$.

Specimens were studied with a JEOL JEM 2100 HRTEM ( $\mathrm{LaB}_{6}$ filament) operating at $200 \mathrm{kV}$ and equipped with an Oxford Instruments INCA X-Sight (model 6498, $30 \mathrm{~mm}^{2}$ ATW2 window, Oxford Inca Suite 4.05 software) EDS system. Images were taken by Gatan Model 794 Slow Scan CCD Camera also by Gatan Model 833 Orius SC200D CCD Camera. A JEOL 31630 side entry, double tilt goniometer was used. Bright field (BF), EDS, SAED, nanobeam diffraction (NBD), and HRTEM were used to study the microstructures. Gatan Digital Micrograph and Diffpack software were used for image processing.

A recent automated technique for the mapping of crystal phases and orientations of polycrystalline materials in a transmission electron microscope was employed to a mixture of nanocrystals and orientation maps for each of the phases [50]. TEM orientation imaging called "ASTAR" (automatic TEM phase orientation mapping) is an automatic phase determination, crystallographic orientation, and indexing tool developed for TEM [51]. This technique is also called as "EBSD (electron backscattered diffraction)-TEM." Electron diffraction (ED) spot patterns are collected sequentially with a dedicated external CCD camera while the sample area (a few square micrometers) is scanned by the primary electron beam. The system also has a precession device "DigiSTAR" and dedicated scan generator to simultaneously precess around the optical axis of the TEM PED (Precession Electron Diffraction).

For automatic TEM phase orientation mapping studies, the samples were also prepared via a focused ion beam (FIB) technique to be thinner and more homogenous. A NanoMEGAS ASTAR DigiSTAR system was used with a camera length of $15 \mathrm{~cm}$, the spot size of $15 \mathrm{~nm}$, and precession angle of 0.7 at NBD mode of TEM. The analyzed square map step was $10 \mathrm{~nm}$. The phases and orientations were identified via image matching between experimental diffraction patterns and calculated templates.

\section{Results and discussion}

Al-Ti-C composites at $943 \mathrm{~K}$ have Al, Ti, C, and

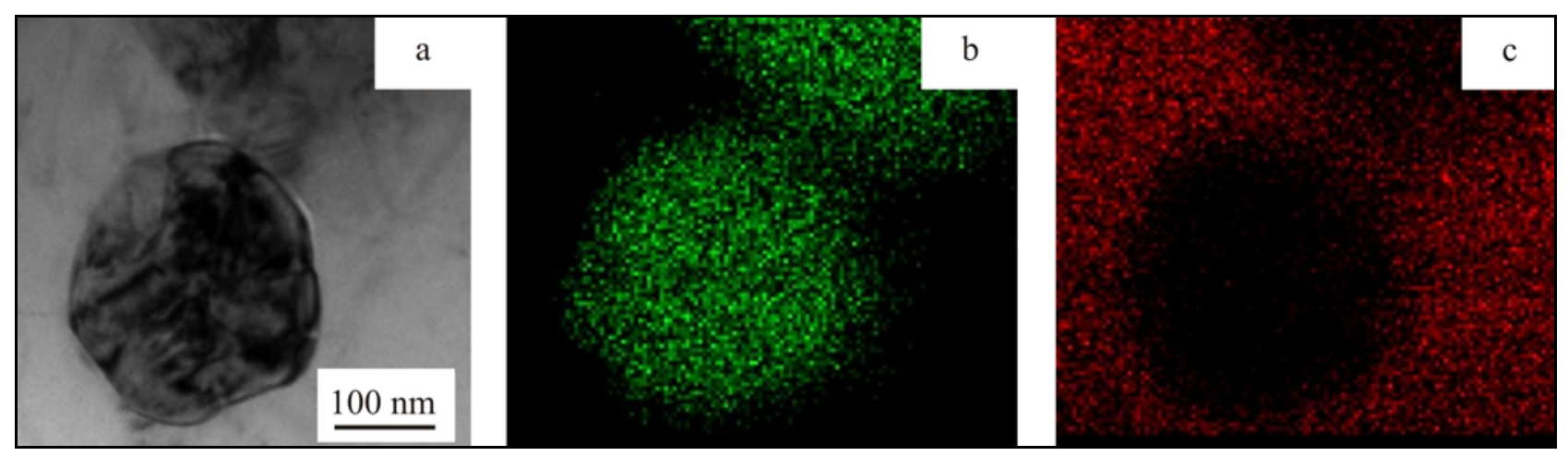

Fig. 7. (a) Bright-field TEM image of round TiC particles, (b) Ti, and (c) Al elemental EDS maps of (a). 


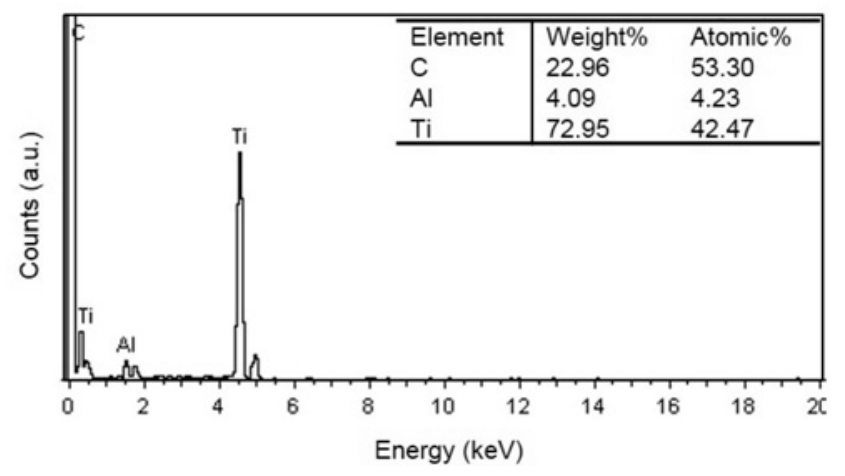

Fig. 8. The TEM-EDS spectrum of TiC particle in Fig. 3.

$\mathrm{TiAl}_{3}$ phases. At $1043 \mathrm{~K}$, an additional $\mathrm{TiC}$ phase appears with XRD. At $1773 \mathrm{~K}$, only the $\mathrm{TiC}$ and
Al phases are found [9]. Similarly, in our study, at $1200^{\circ} \mathrm{C}$, only the $\mathrm{TiC}$ (Fm-3 m space group) secondary phase was observed by XRD (Fig. 1). Therefore, the results of the samples sintered at $1200^{\circ} \mathrm{C}$ were used. They have a single secondary phase. Similar results were also observed by Jiang et al. [32], and they suggest that high production temperatures are necessary for the complete synthesis of $\mathrm{TiC}$ in liquid aluminum. These results suggest that the composite produced at $1200{ }^{\circ} \mathrm{C}$ consists only of in situ $\mathrm{TiC}$ phase, i.e., no other phase is present in the matrix at the chosen sintering time and temperature.

The hardness value was $99( \pm 8) \mathrm{HV}$, which is more than 1.5-fold that of in situ-synthesized pure aluminum samples [49]. SEM studies showed that the second phase $\mathrm{TiC}$ particles were homogenously distributed. The SEM image of $\mathrm{TiC}$ particles and ele-
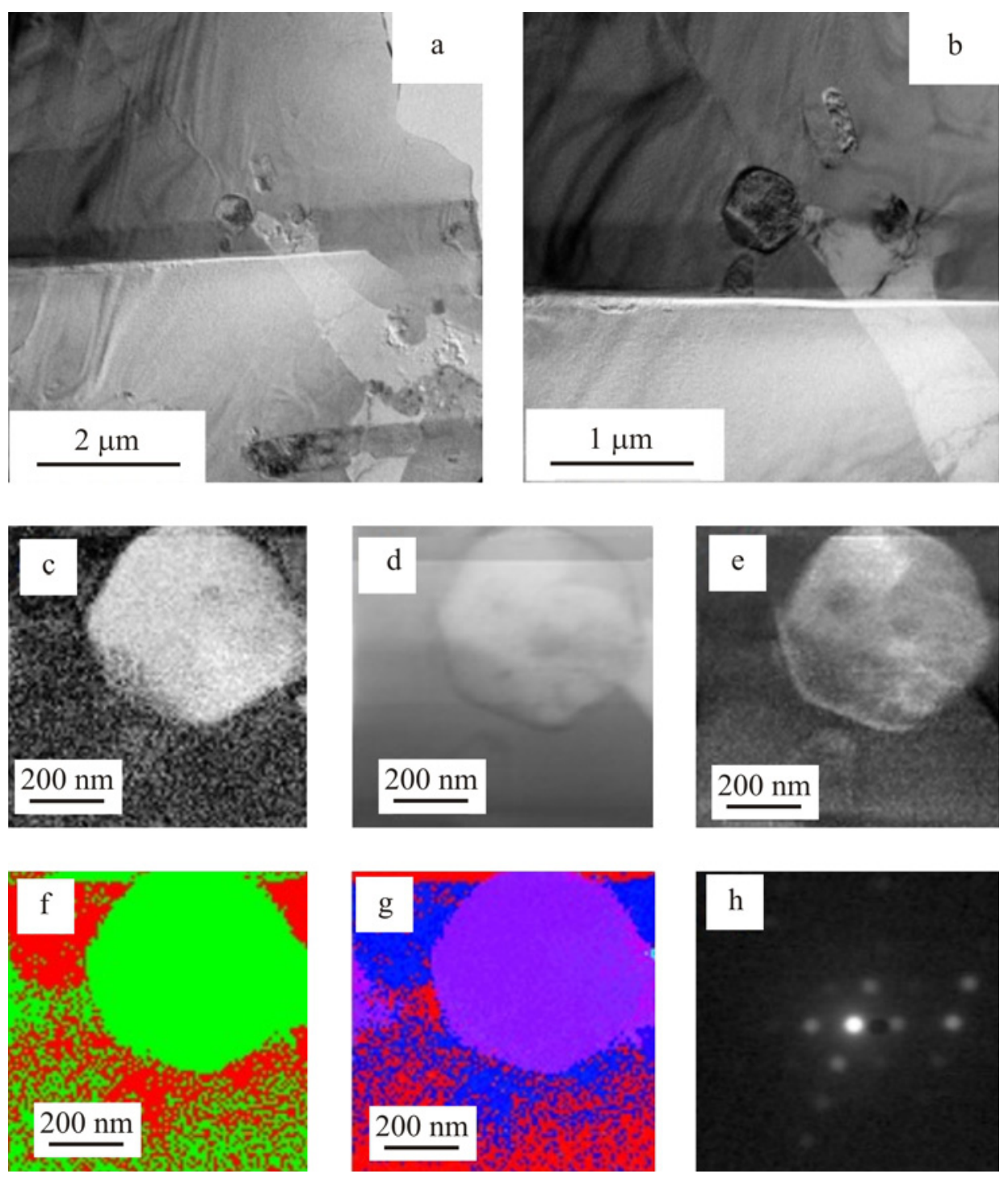

Fig. 9. (a,b) TEM picture of round TiC particle. (c) Phase reliability, (d) virtual BF (bright field), (e) index, (f) phase, and $(\mathrm{g})$ orientation maps; and $(\mathrm{h})$ NBD (nano beam diffraction). 

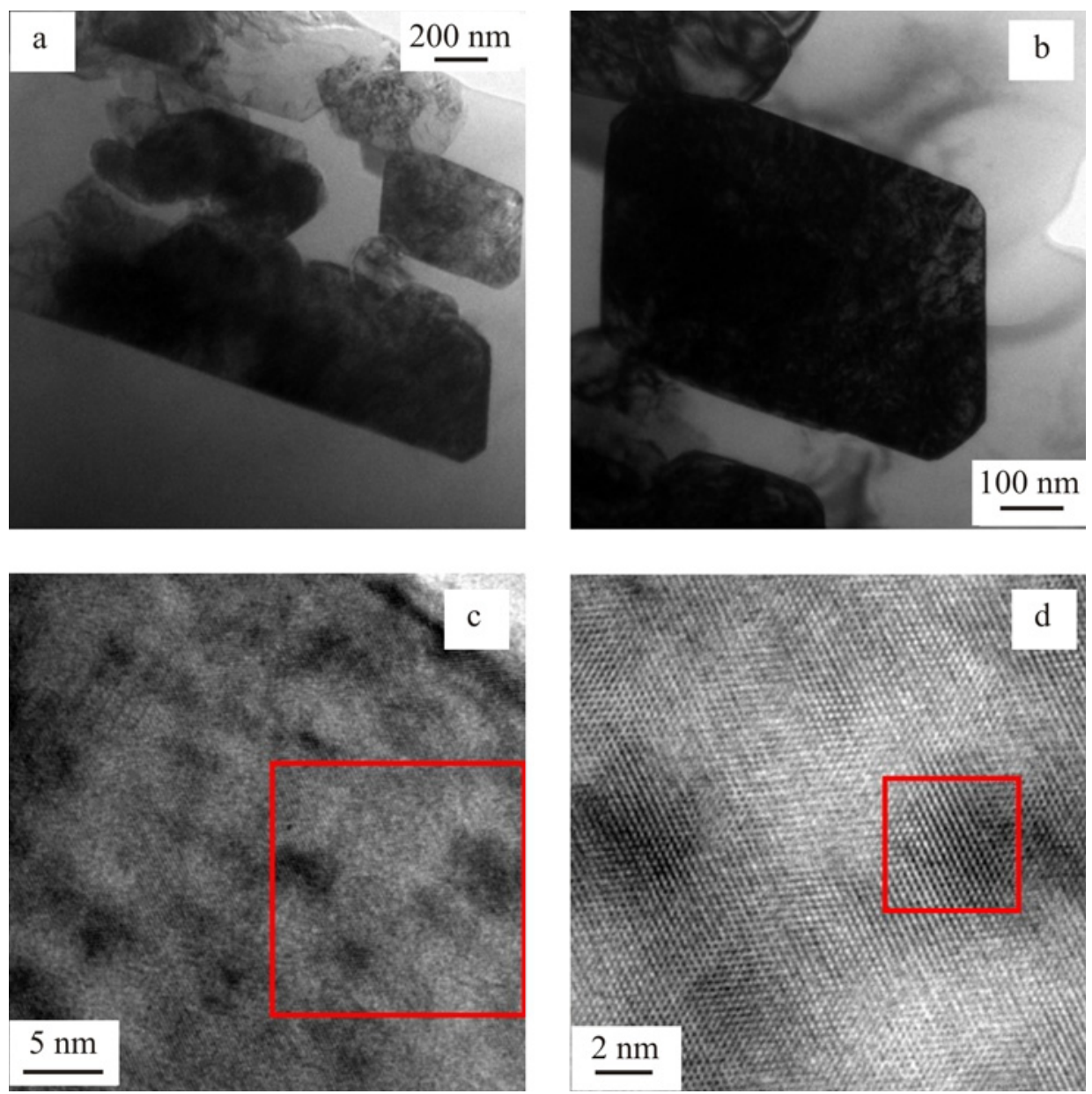

Fig. 10. TEM and HRTEM pictures of rod-like TiC particles.
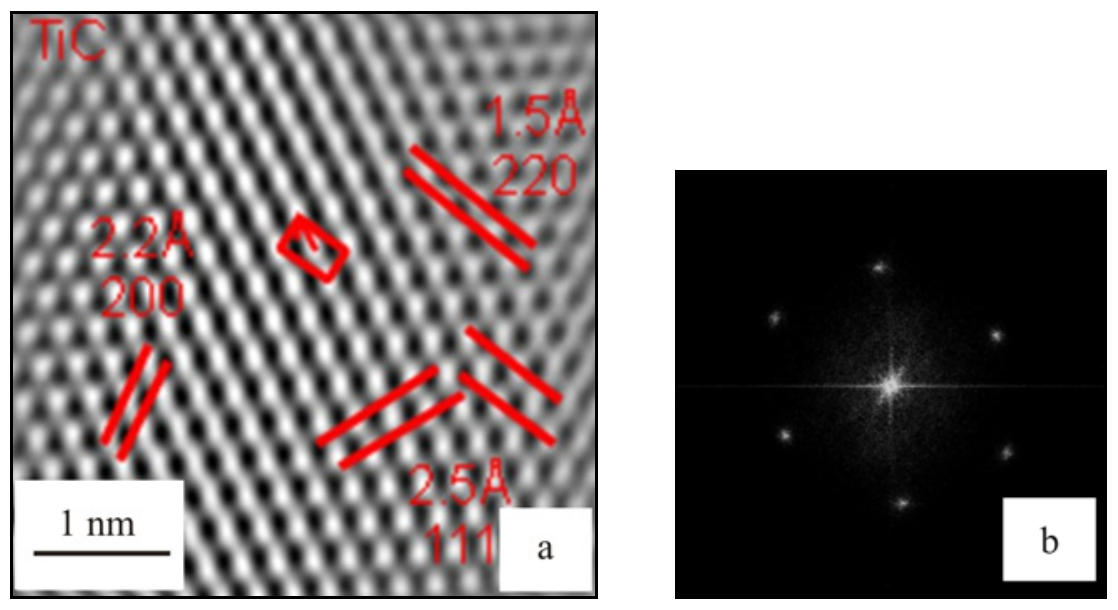

Fig. 11. Atomic lattice image and FFT diffractogram of rod-like $\mathrm{TiC}$ particles.

mental EDS maps from the selected areas are given in Fig. 2. Moreover, no porosity was observed by SEM.

TEM shows mostly nanosized $\mathrm{TiC}$ particles (Fig. 3). However, submicron sized particles were also observed. In Fig. 3 low magnification TEM picture showing particles is given. The TiC particles were round, rod-like, or irregular. Figure 4 shows TEM micrographs of the irregularly shaped $\mathrm{TiC}$ particles.

Figure 5 shows TEM pictures of round $\mathrm{TiC}$ particles. Many dislocation densities are observed at the interface of the particle reinforcement and the aluminum matrix. These round particles are nanometer-sized. 


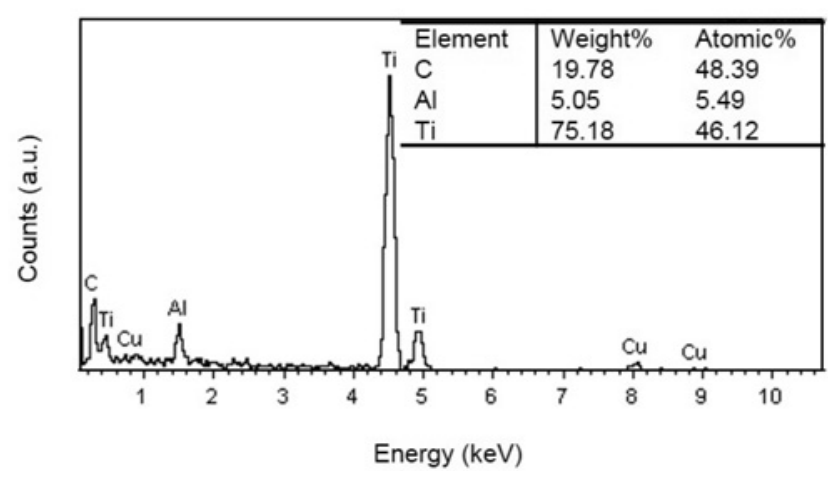

Fig. 12. The TEM-EDS spectrum of rod-like TiC particles.

Similarly, Fig. 6 shows obvious dislocations around irregularly shaped sub-micron TiC particles. More dislocations are found near these particles suggesting that this is related to their size.

Nanoparticles increase the strength of the composites $[37,41]$. Tong et al. also observed dislocation arrays near nano-sized TiC particles formed in situ [20, $38,39]$. They also stated that the particle matrix interfaces were mainly semi-coherent [10, 20].

TEM-EDS was also used to calculate the elemental composition of the particles. EDS elemental mapping of round particles is given in Fig. 7. TEM-EDS (Fig. 8) shows a stoichiometric elemental Ti: $\mathrm{C}(\sim 1: 1)$ atomic ratio of $\mathrm{TiC}$.

Figure 9a shows TEM data of another round $\mathrm{TiC}$ particle. The phase reliability, virtual BF (bright field), index, phase, orientation maps, and NBD (nanobeam diffraction) are given in Fig. 9c-h, respectively. Similar to the TEM-EDS results, the TiC phase is crystallographically obvious.

Rod-like TiC particles were also observed (Fig. 10) by TEM and HRTEM (red squares are magnified views). The HRTEM image of the interface of the TiC particle and aluminum matrix shows good interfacial bonding. The interfaces are mostly clean. Zhang et al. observed clean interfaces between in situ particulates and aluminum matrix [41]. Similarly, Peng et al. observed in situ processes for the clean Al MMC and TiCp-Al interfaces [22].

The indexed atomic lattice image and FFT diffractogram of rod-like $\mathrm{TiC}$ particles (Fig. 10) are shown in un Fig. 11. The zone axis of the particle is [011] of TiC. Similar to round particles, the TEM-EDS of rod-like TiC particles showed a good match with the TiC elemental composition (Fig. 12).

Similarly, the TEM, EDS map, and EDS spectrum of irregularly shaped $\mathrm{TiC}$ particles are given in Fig. 13. The TEM-EDS result shows a stoichiometric $\mathrm{Ti}$ : C atomic ratio of $\mathrm{TiC}(\sim 1: 1)$. Figure 14 a shows a TEM image of irregularly shaped TiC particles similar to Fig. 13. In Figs. 14b-d, different magnification HRTEM images of the aluminum matrix/TiC parti-
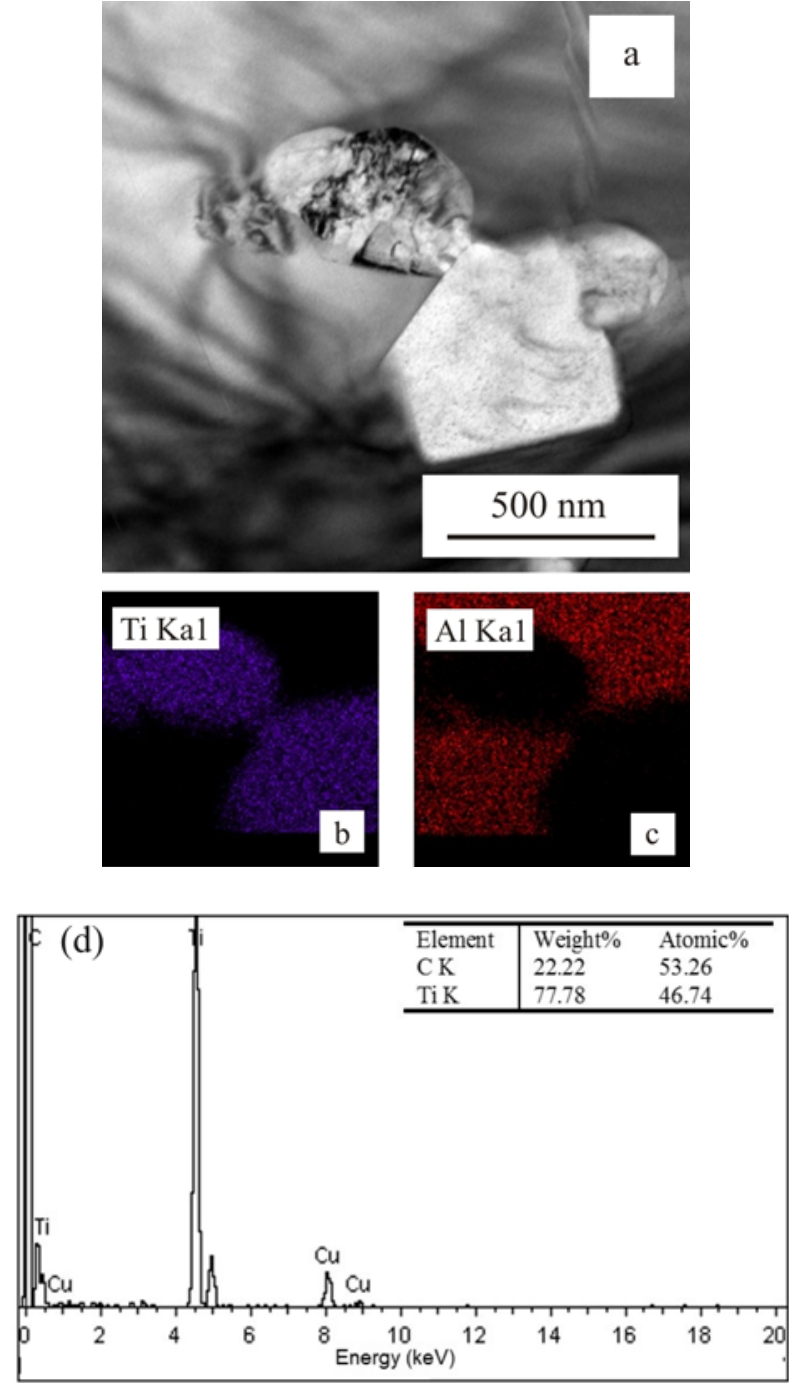

Fig. 13. TEM image, EDS maps, and EDS spectrum of irregularly shaped $\mathrm{TiC}$ particles.

cle interface are shown. Figure 14e is an HRTEM image showing atomic lattice and in Fig. 14f FFT (Fast Fourier Transformation) diffractogram of Fig. 14e is shown. The interface is smooth and clean with no dislocation at the boundary. The Al-TiC interface is coherent (Fig. 14d). No other phase is observed at the boundary.

Titanium carbide has a NaCl-B1 type crystals structure (space group Fm3m) [24, 25]. The lattice mismatch between the $\mathrm{Al}$ matrix and the $\mathrm{TiC}$ particles (4.048 and $4.328 \AA$, respectively) is only $6.92 \%$ $[26]$.

Shi et al. used an in situ spark plasma sinteringreactive sintering (SPS-RS) technique to produce $\mathrm{TiC} / \mathrm{Ti}_{2} \mathrm{AlC} / \mathrm{TiAl}_{3} \mathrm{MMC}$ with a composition of TiC$20 \mathrm{Ti}_{2} \mathrm{AlC}-10 \mathrm{TiAl}_{3}$ (vol.\%). HRTEM-SAED investigations showed a crystal orientation relationship of (0001) $\mathrm{Ti}_{2} \mathrm{AlC} / /(111) \mathrm{TiC}$ and [1210] $\mathrm{Ti}_{2} \mathrm{AlC} / /[110]$ 

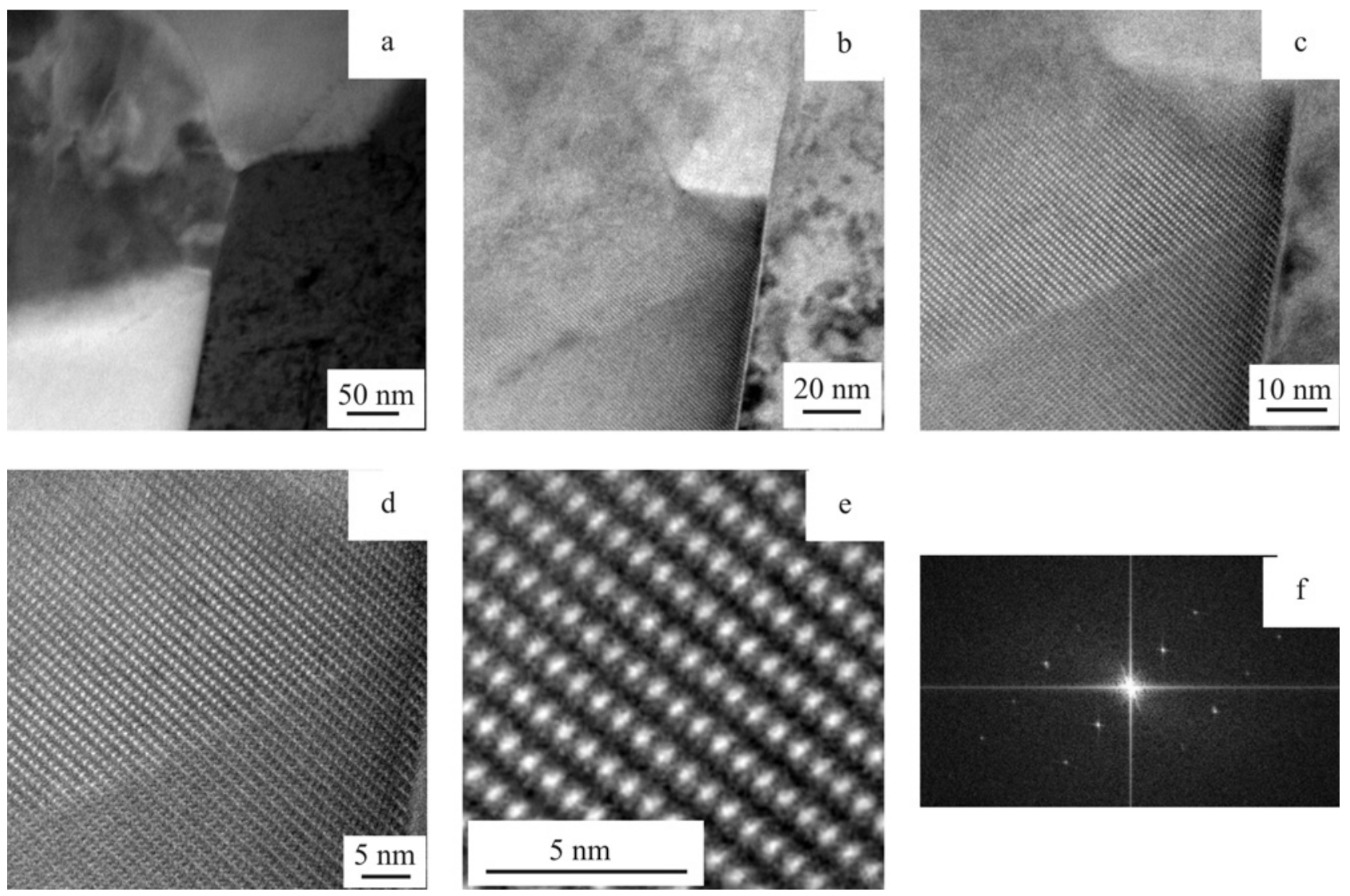

Fig. 14. (a) TEM image of irregularly shaped TiC particles, (b)-(d) different magnification HRTEM images of aluminum matrix TiC particle interface. (e) HRTEM image showing atomic lattice, and (f) FFT (fast Fourier transformation) diffractogram of (e).

TiC. The interfaces were clean with no amorphous phase at the interface [40].

Zhang and colleagues studied $\mathrm{Ti}_{2} \mathrm{AlC} / \mathrm{TiC} / \mathrm{Al}_{2} \mathrm{O}_{3}$ in situ fabricated MMC and observed clean interfaces between the particulates and the metal matrix with TEM [41]. Cui et al. stated that the interfaces of in situ fabricated TiCp-AlNp/Al composites were usually clean, smooth, free of intermediate phases, and well bonded [42]. Also, they used HRTEM to show that the mismatching degree between (111) $\mathrm{Al}$ and (111) $\mathrm{TiC}$ was $18^{\circ}$ [42]. Peng's group used TEM to show that the TiCp-Al interface of $\mathrm{Al}_{2} \mathrm{O}_{3}-\mathrm{TiC} / \mathrm{Al}$ MMCs prepared via the in situ method were clean [22]. Tong et al. investigated in situ reinforced TiC Al MMCs with HRTEM-SAED-CBED and observed a semi-coherent interface $[10,20]$.

Their TEM-SAED investigations showed that the TiC surfaces of the Al-TiC MMC produced by XD technique are parallel to $\left\{\begin{array}{lll}1 & 1 & 1\end{array}\right\}$ and $\left\{\begin{array}{lll}1 & 0 & 0\end{array}\right\}$ planes. These samples are low index and form strong bonds with Al [44-46]. They observed facets and some dislocation arrays at the interfaces. HRTEM studies showed both coherent and semicoherent interface characters depending on the size of the particulates and orientation $[44,45]$.
Phases other than TiC were not found with EDS or SAED in any of the particles, which is consistent with XRD.

In summary, nano-sized $\mathrm{TiC}$ particles and some sub-micron particles were observed in three different geometries. The TEM studies showed coherent and semi-coherent interfaces. Dislocations were mainly observed around particles. A high dislocation density was also seen in some particle-matrix interfaces. The TEM studies show that a clean interface exists between the in situ $\mathrm{TiC}$ reinforcements and the aluminum matrix.

Future studies may focus on better atomic lattice imaging and chemical analysis on the interface with better sample preparation techniques and with advanced electron microscopy instruments [52]. These techniques can also be applied to several Al MMCs and MMCs [53].

\section{Conclusions}

TiC particles were successfully synthesized in liquid aluminum in situ via RHP. The microstructure and properties of the $\mathrm{Al}$ matrix and the $\mathrm{TiC}$ inter- 
face were studied with XRD, hardness testing, SEM, EDS, TEM, and HRTEM. Submicron TiC particles were common. Three types of particles were present: round, rod-like, and irregular. TEM revealed that a clean interface exists between the in situ $\mathrm{TiC}$ reinforcements and the aluminum matrix. Coherent and semi-coherent interfaces with dislocations were also observed. Conventional hot-pressing is a promising candidate to fabricate in-situ metal matrix composites in a cheap and facile way.

\section{Acknowledgement}

The author thanks Prof. Dr. Burak Dikici for supplying the samples.

\section{References}

[1] Fishman, S. G.: JOM, 38, 1986, p. 26. doi:10.1007/BF03257890

[2] Ibrahim, I. A., Mohamed, F. A., Lavernia, E. J.: Journal of Materials Science, 26, 1991, p. 1137. doi:10.1007/BF00544448

[3] Flom, Y., Arsenault, R. J.: Materials Science and Engineering, 77, 1986, p. 191. doi:10.1016/0025-5416(86)90368-X

[4] Howes, A. H. M.: JOM, 38, 1986, p. 28. doi:10.1007/BF03257891

[5] Mortensen, A., Gungor, M. N., Cornie, J. A., Flemings, M. C.: JOM, 38, 1986, p. 30. doi:10.1007/BF03257892

[6] Mortensen, A., Cornie, J. A., Flemings, M. C.: JOM, 40, 1988, p. 12. doi:10.1007/BF03258826

[7] Nardone, V. C., Prewo, K. W.: Scripta Metallurgica, 20, 1986, p. 43. doi:10.1016/0036-9748(86)90210-3

[8] Chow, T. W., Kelly. A., Okura, A.: Composites, 16 , 1985, p. 187. doi:10.1016/0010-4361(85)90603-2

[9] Tjong, S. C., Ma, Z. Y.: Materials Science and Engineering, 29, 2000, p. 49. doi:10.1016/S0927-796X(00)00024-3

[10] Tong, X. C., Ghosh, A. K.: Journal of Materials Science, 36, 2001, p. 4059. doi:10.1023/A:1017946927566

[11] You, C. P., Dollor, M., Thompon, A. W., Bemstein, I. M.: Met. Trans A, 22, 1991, p. 2445. doi:10.1007/BF02665010

[12] Perng, C. C., Hwang, J. R., Doong, J. L.: Composites Science and Technology, 49, 1993, p. 225. doi:10.1016/0266-3538(93)90105-P

[13] Nair, S. V., Tien, J. K., Bates, R. C.: International Metals Reviews, 30, 1985, p. 275. doi:10.1179/imtr.1985.30.1.275

[14] Kai, W., Yang, J. M., Harrigan, W. C.: Scripta Metallurgica, 23, 1989, p. 1277. doi:10.1016/0036-9748(89)90044-6

[15] Rohatgi, P. K.: Key Engineering Materials, 104-107, 1995 , p. 293. https://doi:10.4028/www.scientific.net/KEM

[16] Ma, Z. Y., Bi, J., Lu, Y. X., Shen, H. W., Gao, Y. X.: Composites Interface, 1, 1993, p. 287. https://doi:10.1163/156855493X00121
[17] Kuruvilla, A. K., Prasad, K. S., Bhanuprasad, V. V., Mahajan, Y. R.: Scripta Metallurgica et Materialia, 24, 1990, p. 873 . https://doi:10.1016/0956-716X(90)90128-4

[18] Ma, Z. Y., Tjong, S. C., Gen, L.: Scripta Materialia, 42, 2000, p. 367. https://doi:10.1016/S1359-6462(99)00354-1

[19] Ma, Z. Y., Tjong, S. C., Li, S. X.: Metallurgical and Materials Transactions A, 32, 2001, p. 1019. https://doi:10.1007/s11661-001-0359-4

[20] Tong, X. C.: Journal of Materials Science, 33, 1998, p. 5365. https://doi:10.1023/A:1004494116119

[21] Arsenault, R. J., Taya, M.: Acta Metallurgica, 35, 1987, p. 651. https://doi:10.1016/0001-6160(87)90188-X

[22] Yu, P., Mei, Z., Tjong, S. C.: Materials Chemistry and Physics, 93, 2005, p. 109. https://doi:10.1016/i.matchemphys.2005.02.028

[23] Wu, J. M., Li, Z. Z.: Journal of Alloys and Compounds, 299, 2000, p. 9. https://doi:10.1016/S0925-8388(99)00643-X

[24] Lengauer, W.: In: Handbook of Ceramic Hard Materials. Weinheim, Wiley-VCH 2000. https://doi:10.1002/9783527618217.ch7

[25] Yang, B., Wang, F., Zhang, J. S.: Acta Materialia, 51, 2003, p. 4977. https://doi:10.1016/S1359-6454(03)00292-1

[26] Birol, Y.: Journal of Alloys and Compounds, 454, 2008, p. 110. https://doi:10.1016/j.jallcom.2006.12.016

[27] Birol, Y.: Journal of Alloys and Compounds, 455, 2008, p. 164. https://doi:10.1016/j.jallcom.2007.01.021

[28] Kim, W. J., Yu, Y. J.: Scripta Materialia, 72-73, 2014, p. 25. https://doi:10.1016/j.scriptamat.2013.10.008

[29] Chu, M. G., Premkumar, M. K.: Metall. Trans. A, 24, 1993, p. 2803. https://doi:10.1007/BF02659503

[30] Zhang, E., Zeng, S., Yang, B., Li, Q., Ma, M. A.: Metall. Mater. Trans. A, 30, 1999, p. 1147. https://doi:10.1007/s11661-999-0166-x

[31] Rajan, P. D., Pillai, R. M., Pai, B. C.: J Mater Sci., 33, 1998, p. 3491. https://doi:10.1023/A:1004674822751

[32] Jiang, W. H., Song, G. H., Han, X. L., He, C. L., Ru, H. C.: Mater Lett., 32, 1997, p. 63. https://doi:10.1016/S0167-577X(97)00011-6

[33] Lee, K. B., Sim, H. S., Kwon, H.: Metall. Mater. Trans. A, 36, 2005, p. 2517. https://doi:10.1007/s11661-005-0125-0

[34] Contreras, A., Bedolla, E., Perez, R.: Acta Mater., 52, 2004, p. 985. https://doi:10.1016/j.actamat.2003.10.034

[35] Contreras, A.: Journal of Colloid and Interface Science, 311, 2007, p. 159. https://doi:10.1016/j.jicis.2007.02.041

[36] Tjong, S. C.: Adv. Eng. Mater., 9, 2007, p. 639. https://doi:10.1002/adem.200700106

[37] Valiev, R. Z.: Mater. Sci. Eng. A, 234, 1997, p. 59. https://doi:10.1016/S0921-5093(97)00183-4

[38] Tong, X. C., Fang, H. S.: Metall. Mater. Trans. A, 29 1998, p. 875. https://doi:10.1007/s11661-998-0278-8

[39] Tong, X. C., Fang, H. S.: Metall. Mater. Trans. A, 29, 1998, p. 893. https://doi:10.1007/s11661-998-0279-7

[40] Shi, L., Zhang, J., Wang, L., Jiang, W., Chen, L.: J. 
Mater. Sci. Technol., 27, 2011, p. 239. https://doi:10.1016/S1005-0302(11)60056-X

[41] Zhang, D. L., Cai, Z. H.: J. Am. Ceram. Soc., 89, 2006, p. 3325. https://doi:10.1111/i.1551-2916.2006.00941.x

[42] Cui, C., Li, Y., Wu, R., Greer, A. L.: Composites Science and Technology, 72, 2012, p. 1423. https://doi:10.1016/i.compscitech.2012.05.016

[43] Ma, Z. Y., Li, J. H., Li, S. X., Ning, X. G., Lu, Y. X., Bi, J.: Journal of Materials Science, 31, 1996, p. 741. https://doi:10.1007/BF00367894

[44] Mitra, R., Chiou, W. A., Weertman, J. R., Fine, M. E.: Journal of Materials Research, 8, 1993, p. 2380. https://doi:10.1557/JMR.1993.2380

[45] Mitra, R., Chiou, W. A., Weertman, J. R., Fine, M. E., Aikin Jr., R. M.: Scripta Metallurgica et Materialia, 25,1991 , p. 2689. https://doi:10.1016/0956-716X(91)90140-V

[46] Mitra, R., Mahajan, Y. R.: Bulletin of Materials Science, 18, 1995, p. 405. https://doi:10.1007/BF02749771

[47] Gu, D., Wang, H., Chang, F., Dai, D., Yuan, P., Hagedorn, Y., Meiners, W.: Physics Procedia, 56, 2014, p. 108. doi:10.1016/i.phpro.2014.08.153
[48] Popov, V. A.: Composites Part A: Applied Science and Manufacturing, 145, 2018, p. 57. doi:10.1016/j.compositesb.2018.02.023

[49] Dikici, B., Gavgali, M., Bedir, F.: Journal of Composite Materials, 45, 2011, p. 895. doi:10.1177/0021998310377939

[50] Rauch, E. F., Véron, M., Portillo, J., Bultreys, D., Maniette, Y., Nicolopoulos, S.: Microscopy and Analysis, Issue 93, 2008, p. S5.

[51] Rauch, E. F., Portillo, J., Nicolopoulos, S., Bultreys, D., Rouvimov, S., Moeck, P.: Zeitschrift für Kristallography, 225, 2010, p. 103. doi:10.1524/zkri.2010.1205

[52] Urban, K. W.: Science, 321, 2008, p. 506. doi:10.1126/science.1152800

[53] Howe, J. M.: Interfaces in Materials: Atomic Structure, Thermodynamics and Kinetics of Solid-Vapor, Solid-Liquid and Solid-Solid Interfaces. New York, Wiley-Interscience 1997. 